\title{
An Evaluation Study on Investment Efficiency: A Predictive Machine Learning Approach
}

\author{
Weiwei Hao $(\mathbb{D}$, Hongyan Gao $\mathbb{D}$, and Zongqing Liu \\ School of Economics and Management, Beijing Jiaotong University, Beijing, China \\ Correspondence should be addressed to Weiwei Hao; wwhao@bjtu.edu.cn
}

Received 26 December 2020; Revised 7 January 2021; Accepted 18 January 2021; Published 8 February 2021

Academic Editor: Abd E.I.-Baset Hassanien

Copyright (C) 2021 Weiwei Hao et al. This is an open access article distributed under the Creative Commons Attribution License, which permits unrestricted use, distribution, and reproduction in any medium, provided the original work is properly cited.

\begin{abstract}
This paper proposes a nonlinear autoregressive neural network (NARNET) method for the investment performance evaluation of state-owned enterprises (SOE). It is different from the traditional method based on machine learning, such as linear regression, structural equation, clustering, and principal component analysis; this paper uses a regression prediction method to analyze investment efficiency. In this paper, we firstly analyze the relationship between diversified ownership reform, corporate debt leverage, and the investment efficiency of state-owned enterprises (SOE). Secondly, a set of investment efficiency evaluation index system for SOE was constructed, and a nonlinear autoregressive neural network approach was used for verification. The data of A-share state-owned listed companies in Shanghai and Shenzhen stock exchanges from 2009 to 2018 are taken as a sample. The experimental results show that the output value from the NARNET is highly fitted to the actual data. Based on the neural network model regression analysis, this paper conducts a descriptive statistical analysis of the main variables and control variables of the evaluation indicators. It verifies the direct impact of diversified ownership reform on the investment efficiency of SOE and the indirect impact on the investment efficiency of SOE through corporate debt leverage.
\end{abstract}

\section{Introduction}

Under the complete market hypothesis, the company's investment decisions are only related to investment opportunities, not to financing methods. However, due to information asymmetry, agency conflict, financing constraints, and other factors in the real market, the company's debt ratio will directly affect the company's investment decisions, resulting in that the company's actual investment scale deviates from the optimal investment scale, resulting in the inefficient investment situation of underinvestment or overinvestment.

Early studies began with the debt leverage and corporate investment efficiency from the agency conflict theory and contingency governance theory. From the agency conflict theory, the agency conflict between shareholders and creditors caused by liabilities often leads shareholders or managers to make investment decisions that damage the interests of creditors and then lead to investment distortion. Jensen and Meckling [1] and Myers [2] put forward the problem of low investment efficiency from the perspective of the conflict of interests between creditors and shareholders. In other words, in the financing structure with high financial leverage, managers, as one of the shareholders, have strong motivation to engage in high-risk investment projects. Starting from the theory of contingent governance, debt can reduce the agency costs caused by conflicts between shareholders and managers through the supervision and management by creditors, thereby effectively restraining managers from making investment decisions that damage shareholders' rights. Tirole [3] believed that debt constraints can urge companies to use free cash flow for investment projects with positive net present values, instead of being consumed by management at will or investing in projects with negative net present values. Managers who face liquidity shortages caused by debt constraints will be more cautious and careful in project investment, which will help to improve the company's investment efficiency.

The current analysis is mostly based on the premise of hard budget constraints. Sun and $\mathrm{Li}$ [4] examined the investment of research funds at universities and six variables were selected as evaluation indicators from the perspective 
of fixed assets, teaching configuration, research instruments, and the number of books in libraries. Through empirical analysis, $\mathrm{Li}$ and others [5] believe that most of the nonfinancial listed companies in China have excessive investment behaviors, showing inefficiency of investment. The greater the absolute amount of annual increase in debt, the more serious the inefficiency of corporate investment. The smaller the ratio of debt to debt is, the more likely it is to cause underinvestment in the enterprise.

It had been proved that the latest developments in data science and machine learning have the potential to improve investment decisions. Many scholars have used machine learning methods to research and evaluate smart investment strategies. Li Liang and Wang Jia [6] analyzed the investment efficiency of China Merchants Bank's smart investment based on K-means cluster analysis and data mining technology and proved that the method is suitable for efficiency analysis of other smart investment products. The linear regression, decision tree, random forest, neural network, and XGBoost models were applied to analyze the efficiency of more than 10,000 companies in Li et al.'s work [7]. They proposed an interpretable machine learning algorithm for intelligent decision-making problems to predict the innovation efficiency of the enterprise [7]. Bhagchandani [8] used machine learning to reveal the gap between financial ecosystems and designed a basic algorithm to analyze the graphical structure of the financial market, using logistic regression to determine the validity of predictions.

Different scholars have done a lot of research on the investment efficiency of state-owned enterprises using machine learning methods from different perspectives, including exploring the impact on corporate investment efficiency from the debt and analyzing the impact on corporate investment efficiency from the perspective of diversified ownership reform. These have laid a good foundation for the study of this paper. However, the existing research on the relationship between diversified ownership reform, debt leverage, and investment efficiency of state-owned enterprises mainly focuses on the relationship between the two, and a few works have connected the above three.

Starting from the theory of capital structure, this paper analyzes the relationship among diversified ownership reform, corporate debt leverage, and investment efficiency of state-owned enterprises and establishes a comprehensive index evaluation system for investment efficiency. We used the diversified ownership reform and corporate debt leverage as impact factors, used the entropy method for data processing and analysis, used a neural network for training samples, and established an investment efficiency evaluation model based on NARNET.

We use NARNET to conduct regression analysis and evaluation on the investment efficiency of state-owned enterprises and draw conclusions about the influence of diversified ownership reform and corporate debt leverage on the investment efficiency of state-owned enterprises.

The second part of this paper gives an overview of the related research of machine learning applied in the field of efficiency evaluation. In the third part, we establish the investment efficiency evaluation index system, process the sample data set of state-owned listed companies, and establish the NARNET model. In the fourth part, the neural network is trained to achieve the desired effect and the regression analysis is performed on sample data. Finally, the conclusion of this paper is given in the fifth part.

\section{Related Work}

In recent years, machine learning has achieved many successes in the fields of image and face recognition, speech recognition, natural language processing, recommendation systems, and so forth. In terms of efficiency evaluation, the use of machine learning has also become a hot topic in related research.

Apipie and Georgescu [9] applied multiobjective optimization metaheuristics to solve a portfolio optimization problem. By analyzing the characteristics of listed real estate companies and the ideological basis of the support vector machine theory, they designed the evaluation index selection principle, formed the evaluation index system composed of ten indexes, and established the support vector machine regression model. Liu [10] proposed a performance auxiliary analysis system based on text analysis, using machine learning based on SVM, Naive Bayes, K-nearest neighbors, and other text classification algorithms to classify the roles of government officials, and established a quantitative role evaluation system. It provides a more objective and scientific reference for the establishment of the performance appraisal system on the e-government system based on the natural interaction mode.

Li proposed using SVM to solve the advantages of a small-sample, nonlinear, and high-dimensional pattern recognition to evaluate and analyze stock quantitative investment [11]. In Wu's work, the Stackelberg game model of green investment decision-making among enterprises is established by considering the case of the supplier's green investment alone and the case of the manufacturer and the supplier's joint green investment. The influence of green uncertainty on enterprise's decision-making is analyzed [12]. The previous studies' results proved that the machine learning method is in the performance evaluation system and the model has good applicability. Lin et al. put forward a new type of multiobjective optimization method for performance evaluation problems using the K-means algorithm to classify the evaluation objects and then construct the satisfaction function [13]. Based on the above work, they established a multiobjective optimization model to evaluate the satisfaction of the object. The results prove that the scalar model can obtain a weakly effective solution. Song [14] constructed a fuzzy chance-constrained leastsquares twin support vector machine (FCC-LSTSVM) in business performance prediction. Ahmed [15] determined the standard rules of the best KPI for e-commerce websites based on Google Analytics and decision tree algorithm. Heilbrunn [16] used the machine learning method of the alternating diffusion process to study the impact of strategic planning on the performance of service-oriented small- and medium-sized enterprises (SMEs). This method applies two business data sets, which are strategic planning data and performance data. 
$\mathrm{Li}$ and others constituted the evaluation index system of the fundamental innovation performance of the enterprise from the six dimensions of resources, technology, products, management, commercial value, and social value [17]. They established a performance evaluation model and trained the model applying BP neural network and finished the simulation verification of the fundamental innovation performance evaluation of sample enterprises. Wang used RS-MultiBoosting as a hybrid integrated machine learning (HEML) method to help companies make correct business decisions and assessments between NPD (new product development) incremental strategies and aggressive NPD strategies to improve NPD's overall performance [18].

Different from the methods mentioned above, this paper does not directly apply a nonlinear recurrent neural network with external inputs method to efficiency evaluation. Because of the efficiency of state-owned enterprises as a complex system, direct data-based learning is not enough to have a better explanation. In this paper, we used the advantages of the entropy method in data processing to determine the weight of the initial weight of each indicator. The NARNET is used to evaluate the regression method of state-owned enterprise investment efficiency. Experiments show that the NARNET model is more consistent with data simulation. We verified the relationship between diversified ownership reform, corporate debt leverage, and other factors and the investment efficiency of state-owned enterprises. The results verify that this method is effective and applicable.

\section{Method}

3.1. Outline. The relationship among mixed ownership reform, corporate debt, and corporate efficiency is based on the following analysis.

Diversified ownership reforms have an impact on SOE debt mainly through the following ways: (1) Through diversified ownership reforms, non-state-owned capital is added, and the capital scale of enterprises is expanded. It can reduce the asset liability ratio of state-owned enterprises when the total debt scale of enterprises remains unchanged. At the same time, enterprises can also use this part of the expanded funds to give priority to debt repayment, so as to reduce the debt ratio of enterprises and achieve the purpose of reducing debt. (2) Diversified ownership reforms can indirectly reduce the debt of SOE by improving corporate governance. By improving the corporate governance system and strengthening the market-oriented operation, shareholder supervision will be more adequate, which will change the situation of excessive debt of enterprises, and promote enterprises to return to a healthy level of asset liability ratio.

The investment efficiency of state-owned enterprises is mainly affected by the following ways. The introduction of non-state-owned capital by SOE through diversified ownership reforms can play a supervisory role in the management, so that the management can make more scientific and reasonable investment decisions, reduce ineffective and irrational investment behavior, and improve the investment efficiency of state-owned enterprises.
Through the above analysis, diversified ownership reforms are conducive to reducing the debt of SOE, and reducing the debt of state-owned enterprises is conducive to improving the investment efficiency of enterprises. Furthermore, it can be seen that diversification can not only directly affect the efficiency of investment but also indirectly affect the efficiency of investment.

The investment efficiency of enterprises is a complex system. However, the existing research on investment efficiency is from an explanatory point of view, which is lack of comprehensiveness. In this paper, we propose a predictive method to test our hypothesis through a regression neural network.

The process of building a neural network model is given in Figure 1. As shown in Figure 1, we first choose the evaluation index of investment efficiency, which may directly or indirectly affect the investment efficiency. We complete this work through empirical method. Next, we use entropy method to determine the weight of each index. The above work can only explain the relationship between each index and investment efficiency. Finally, we train a regression neural network model. We use predictive methods to verify the comprehensive relationship between these indicators and investment efficiency.

3.2. Construction of the Model Indicator System. To build a comprehensive evaluation model of the investment efficiency of state-owned enterprises, we should first determine the model index according to the theoretical basis of enterprise debt and investment.

The explained variable in this study is investment efficiency. This paper draws on Richardson's [19] expectation model to estimate investment efficiency and uses the absolute value of the residual estimated by the regression model to measure inefficient investment. With lower efficiency, the residual value greater than zero indicates overinvestment, and the residual value less than zero indicates underinvestment. Therefore, the higher the degree of inefficient investment, the lower the investment efficiency.

3.2.1. Total Investment. $\operatorname{Inv}_{i, t}$ represents the total investment of company $i$ in year $t$ :

$$
\operatorname{Inv}_{i, t}=\frac{\text { capital expenditure of } i}{\text { total assets at the end of } t} \times 100 \% .
$$

3.2.2. Investment Opportunities. $\mathrm{Grow}_{i, t-1}$ represents investment opportunities, expressed by the growth rate of company $i$ operating income in year $t-1$.

3.2.3. Liabilities. $\operatorname{Lev}_{i, t-1}$ represents company $i$ debt situation in year $t-1$, expressed in terms of asset-liability ratio.

3.2.4. Current Cash Situation. Cash $_{i, t-1}$ indicates the current cash situation of a company $i$ in year $t-1$ : 


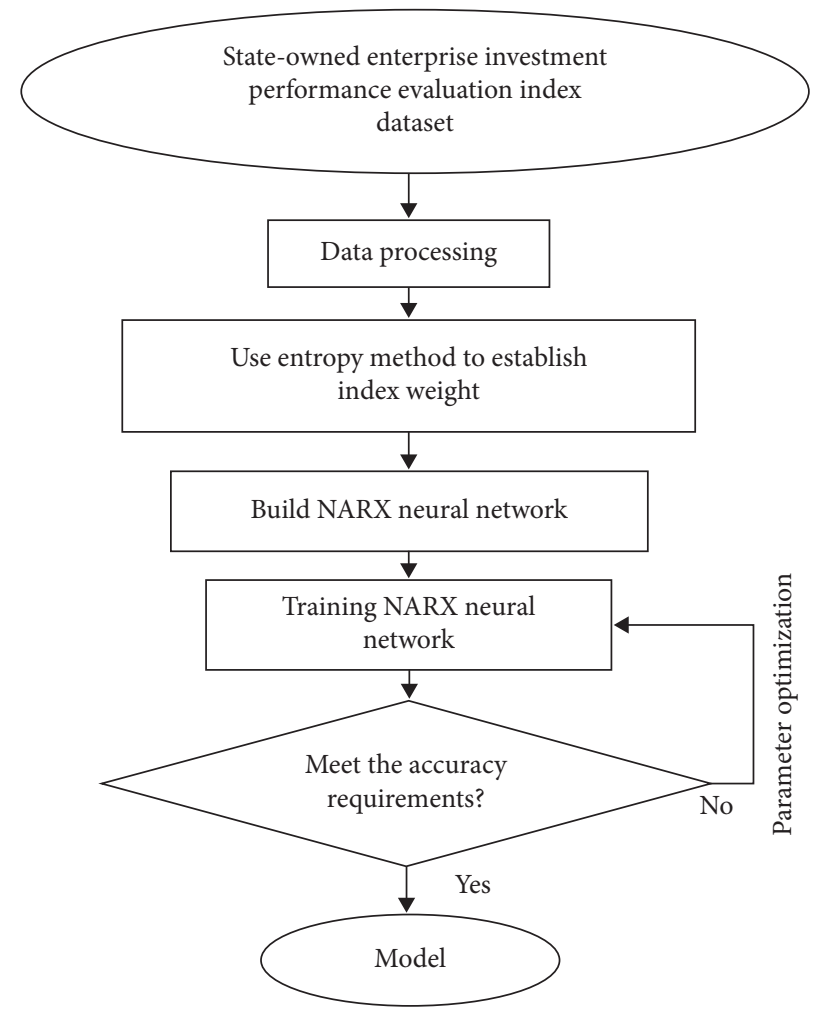

FIgURE 1: Flow chart of neural network establishment.

$$
\text { Cash }_{i, t-1}=\frac{\text { currency assets } i \text { at the end of } t-1}{\text { total assets at the end of } t-1} \times 100 \% \text {. }
$$

3.2.5. Listing Years. Age $\mathrm{A}_{i, t-1}$ indicates the length of company $i$ listing period at the end of period $t-1$.

3.2.6. Company Size. Size ${ }_{i, t-1}$ represents the size of the company; the calculation method is that the company's total assets at the end of the year take the natural logarithm:

$$
\text { Size }_{i, t-1}=\log \text { (company total assets at the end of the year). }
$$

3.2.7. Profitability. $A r_{i, t-1}$ indicates the profit level of company $i$ in year $t-1$, expressed by basic earnings per share.

3.2.8. Dummy Variables. We use Ind and Year as dummy variables of industry and year to remove the influence caused by different years and industries.

To comprehensively measure the degree of diversified ownership reform of state-owned enterprises, four variables in the process of diversified ownership reform of stateowned enterprises (Var), depth (Dep), degree of integration (Mix), and degree of checks and balances (Res) are selected as the diversified ownership reform explanatory variables.
We selected the interest-bearing debt ratio indicator (Debr) to express the debt leverage of the company [20], only considering two ways of loans and bonds and using total assets for standardized treatment.

As explained above, this paper selects the following control variables: company size (Size), which is the natural logarithm of the total assets at the end of the period; cash holdings (Cash), which are the total monetary capital holdings divided by the total assets at the end of the period; and asset-liability ratio (Lev), which is the total liabilities at the end of the period divided by the total assets at the end of the period. Besides, this paper also eliminates the effects of annual dummy variables (Year) and industry dummy variables (Industry).

3.3. Data Sample Processing. The research in this paper selects the relevant data of A-share listed companies in Shanghai and Shenzhen stock exchanges from 2009 to 2018 as the initial sample, which was processed according to the following criteria:

(1) Selecting A-share state-owned listed companies in Shanghai and Shenzhen stock exchanges according to the nature of the actual controller;

(2) Excluding enterprises that belong to the financial industry;

(3) Excluding ST and *ST companies. The operating conditions of these companies are deteriorating, and some of their financial indicators deviate from the normal listing requirements. Therefore, the risk of 
taking these companies as samples will affect the results more often;

(4) Excluding sample companies that have been listed for less than 5 years to weaken the impact of abnormal changes in investment efficiency caused by listing;

(5) Eliminating companies with missing relevant indicator data. To control the influence of extreme values on the results of the study, a 1\% Winsorized extreme value processing was performed at both ends of the data.

At the same time, this paper selects $10 \%$ as the cut-off point and excludes the case where the non-state-owned constituents hold no more than $10 \%$ of the shares in stateowned enterprises [21]. 393 samples and 3930 observations were finally obtained.

Due to the large actual value of asset-related index data, the network training convergence will be slow and the training time will be too long. That will lead to the bad efficiency of the model. Therefore, it is required to normalize the larger data. This paper uses the max-min method for processing:

$$
x=\frac{x-x_{\min }}{x_{\max }-x_{\min }} .
$$

To provide a basis for the comprehensive evaluation of multiple indicators, this paper uses the entropy method to determine the initial weight of each indicator. The process is as follows:

(1) Establishing an indicator data matrix:

$$
A=\left[\begin{array}{ccc}
x_{11} & \cdots & x_{1 m} \\
\vdots & \ddots & \vdots \\
x_{n 1} & \cdots & x_{n m}
\end{array}\right]_{n * m} .
$$

For a sample of $n$ enterprises and $m$ indicators, $X_{i j}$ is the value of the $j$-th indicator of the enterprise $i(i=1$, $2, \ldots, n ; j=1,2, \ldots, m)$.
(2) Data standardization:

The same max-min method as above is used to perform data translation processing on the indicator.

(3) It requires the proportion of the $j$-th index value of the $i$-th company to calculate the index entropy.

$$
y_{i j}=\frac{x_{i j}^{\prime}}{\sum_{i=1}^{n} x_{i j}^{\prime}} .
$$

(4) To calculate the information entropy of the $j$-th index, the formula is

$$
e_{j}=-k \sum_{i=1}^{m} y_{i j} \ln y_{i j},
$$

$k$ is a constant. $k=(1 / \ln m)$.

(5) Calculating the difference coefficient of the $j$-th index:

$$
d_{j}=1-e_{j} .
$$

(6) The weight of the jth index is

$$
w_{j}=\frac{d_{j}}{\sum_{j=1}^{m} d_{j}}, \quad j=1,2 \ldots m .
$$

Finally, $W=\left\{w_{1}, w_{2}, \ldots, w_{m}\right\}$ is the objective weight value of each indicator.

3.4. NARNET. In this paper, NARNET is a nonlinear autoregressive neural network with external inputs. A typical NARNET is mainly composed of the input layer, hidden layer, output layer, and input delay function. The basic structure of the model is shown in Figure 2.

The difference between NARNET and an ordinary neural network is that the former adds a delay function before the hidden layer. The output layer of the neural network receives feedback from the hidden layer, which can be described as

$$
y(t+1)=f[y(t), y(t-1), \ldots, y(t-n y+1), u(t), u(t-1), \ldots, u(t-n u+1, W)]=f[y(t), u(t), W]
$$

In the NARNET, the output signal is delayed and then is input into the neural network; through the hidden layer and the output layer, the final output result is obtained. Taking $i$ as the amount of input data and $j$ as the number of hidden layer neurons, $x_{i}$ represents the $i$-th input signal of the network, and $w_{i j}$ represents the connection weight between the $i$-th output delay signal and the $j$-th neuron. $a_{j}$ represents the threshold value of the $j$-th hidden layer neuron, and the hidden layer activation function $f$ is synthesized to obtain the calculation results of each neuron:

$$
d_{j}=f\left(\sum_{i=1}^{n} w_{i j} x_{i}+a_{j}\right) .
$$

Then the model takes $w_{j}$ as the connection weight between the $j$-th neuron in the hidden layer and the output layer neuron and $b$ as the output layer neuron threshold. The output result is calculated as follows:

$$
o_{j}=f\left(\sum_{j=1}^{n} w_{i j} d_{i}+b\right) \text {. }
$$




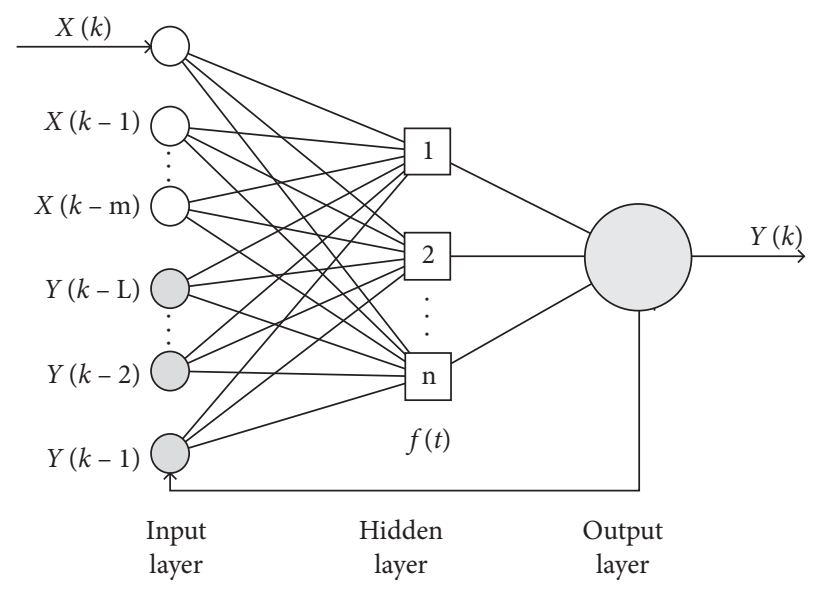

FIgURE 2: The structure of the NARNET.

\section{Results and Discussion}

According to the above training data set, the entropy method is used to calculate the weight of each evaluation index, as shown in Figure 3. Preliminary analysis shows that the contributions of investment indicators, diversified ownership reform, and corporate debt leverage to the evaluation model are about $3 / 5,1 / 5$, and $1 / 5$, respectively.

According to the evaluation index system established in the previous section, we collect $\mathrm{x} 1$ (total investment volume), x2 (investment opportunities), x3 (debt situation), x4 (liquid cash situation), x5 (length of listing period), x6 (company size), x7 (profit level), x8 (dummy variable (industry)), x9 (dummy variable (year)), x10 (equity diversity), x11 (equity depth), x12 (equity mixing degree), x13 (equity balance), and x14 (interest-bearing debt ratio) to constitute the enterprise investment efficiency evaluation data table in Table 1.

This paper takes the first indicator in the model evaluation indicator system as the output and the remaining indicators as the input. The BP algorithm was taken as the network training method and the number of hidden layer neurons is set to 14 , and the delay is set to 2. It can be seen from Figure 4 that the network has reached the setting accuracy and has a good fitting to the sample data. So the training of the model is ideal. Figure 5 shows the error autocorrelation function of this network. It can be seen from Figure 6 that the error autocorrelation function is within the confidence interval except for individual special data. So the network is well trained.

It can be seen from Figure 4 that the output value from the NARNET is highly fitted to the actual data. Based on the neural network model's regression analysis, this paper conducts a descriptive statistical analysis of the main variables and control variables of the evaluation indicators. It verifies the direct impact of diversified ownership reform on the investment efficiency of state-owned enterprises and the indirect impact on the investment efficiency of state-owned enterprises through corporate debt leverage. The model independently estimates the impact of state-owned enterprise debt leverage on enterprise investment efficiency, and the results are given in Table 2.

The results show that corporate debt leverage and corporate investment efficiency are in an inverted U-shaped relationship. Initially, as corporate debt leverage increases, corporate investment efficiency will increase. After reaching a certain peak, as corporate debt leverage continues to increase, the level of investment efficiency began to decline. This shows that corporate debt leverage has a certain limit; it is not that the higher the better.

State-owned enterprises not only undertake economic goals such as promoting economic growth but also bear the responsibility of promoting employment and maintaining social stability; therefore, inefficient investment was often made in these companies. Chen and Dong [22] believe that the government's distorted market mechanism has hindered the development of the state-owned economy. Du et al. [23] have shown that political connections will reduce the efficiency of corporate investment. State-owned enterprises introduced nonstate capital through the implementation of mixed-ownership reform to optimize the ownership structure. This is helpful for enterprises to make correct business decisions, reduce inefficient investment behavior, and improve the investment efficiency of state-owned enterprises. Besides, the diversified ownership reform has expanded the capital scale of enterprises. Therefore, the debt ratio of the enterprise can be reduced, and the purpose of deleveraging can be achieved. The addition of nonpublic components dilutes the state-owned components, which increases the debt cost of diversified-ownership enterprises to a certain extent, thereby reducing the debt leverage ratio of enterprises.

According to the trade-off theory, appropriate debt will bring tax benefits to the enterprise. When the company's asset-liability ratio is low, the company can moderate debt to ease the financing constraints of the company and meet the needs of the company's investment expansion, thereby curbing the underinvestment of the company and improving the efficiency of the company's investment. When the cost of debt is greater than the mitigation effect of debt financing on corporate financing constraints, this will increase the cost of 


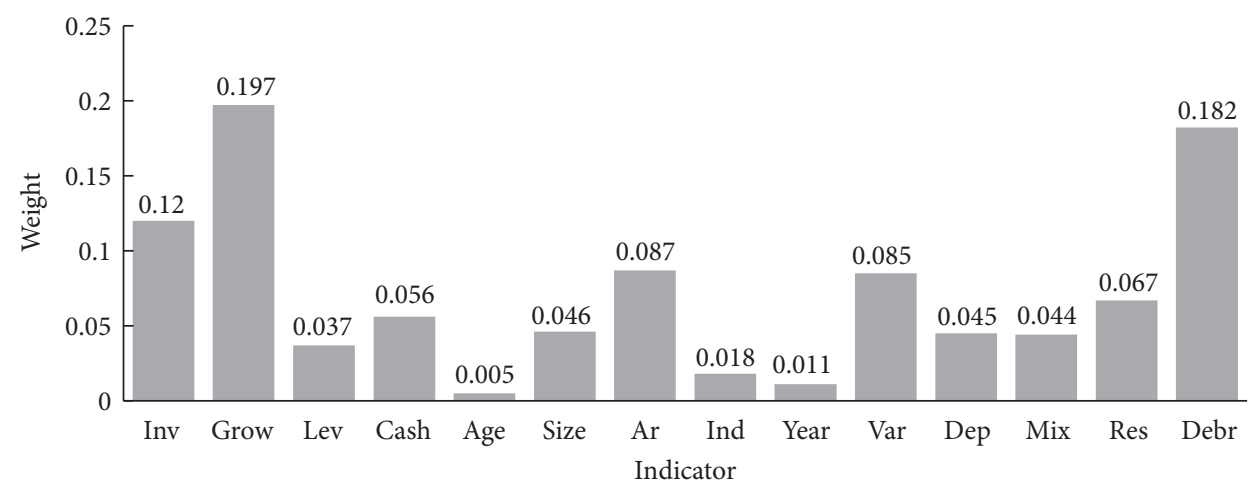

Figure 3: Indicator weight diagram.

TABLE 1: Investment efficiency evaluation data sheet.

\begin{tabular}{|c|c|c|c|c|c|}
\hline \multicolumn{6}{|c|}{ Sample } \\
\hline Indicator & 1 & 2 & 3 & $\ldots$ & 4324 \\
\hline $\mathrm{x} 1$ & 0.1805 & 0.2493 & 0.0695 & & 12.0348 \\
\hline $\mathrm{x} 2$ & 0.1538 & -0.0022 & 0.6788 & & 0.0029 \\
\hline $\mathrm{x} 3$ & 0.6744 & 0.7166 & 0.7435 & & 0.4568 \\
\hline $\mathrm{x} 4$ & 0.1675 & 0.0263 & 0.1649 & & 0.1398 \\
\hline $\mathrm{x} 5$ & 29 & & & & 13 \\
\hline$x 6$ & 0.255 & & & & 0.237 \\
\hline $\mathrm{x} 7$ & 0.4219 & & & & 0.6609 \\
\hline $\mathrm{x} 8$ & 1 & & & & 12 \\
\hline $\mathrm{x} 9$ & 2009 & & & & 2009 \\
\hline $\mathrm{x} 10$ & 0.7166 & & & & 0.4896 \\
\hline $\mathrm{x} 11$ & 0.7435 & & $\ldots$ & & 0.517 \\
\hline $\mathrm{x} 12$ & 0.0695 & & & & 0.7015 \\
\hline $\mathrm{x} 13$ & 0.1649 & & & & 0.3108 \\
\hline $\mathrm{x} 14$ & 0.1398 & & & & 0.6071 \\
\hline
\end{tabular}

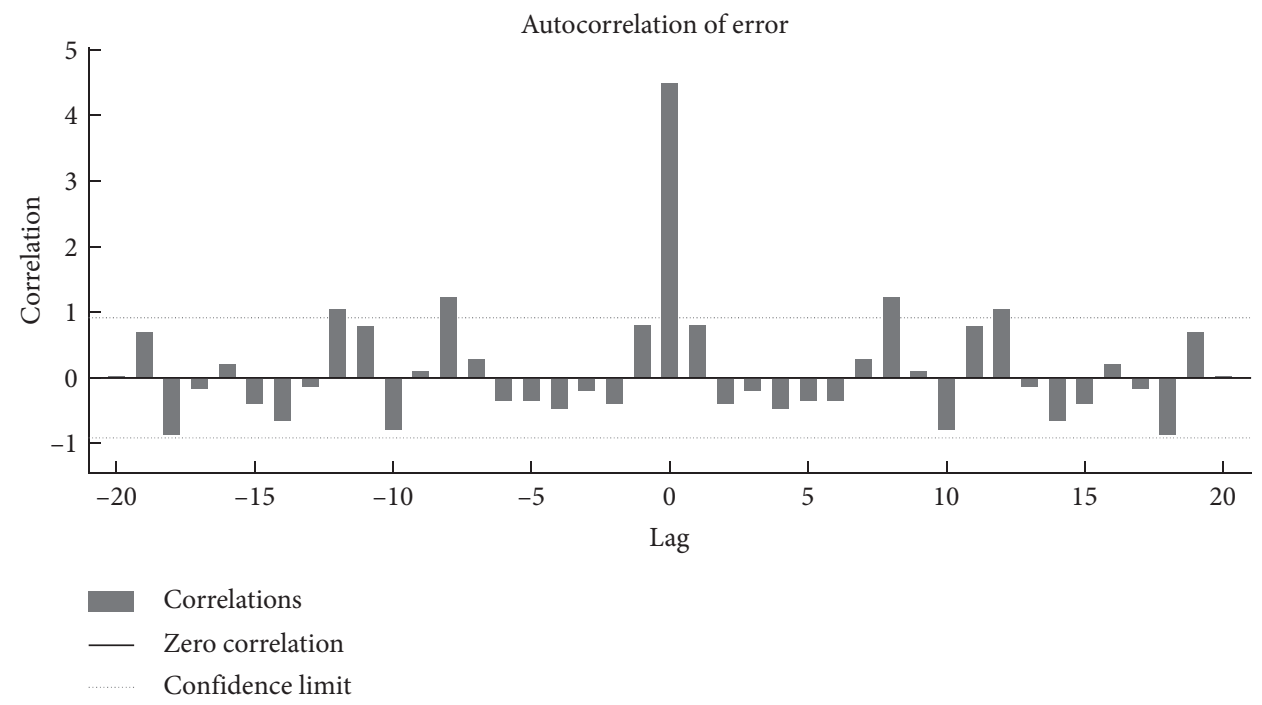

Figure 4: Autocorrelation error. 


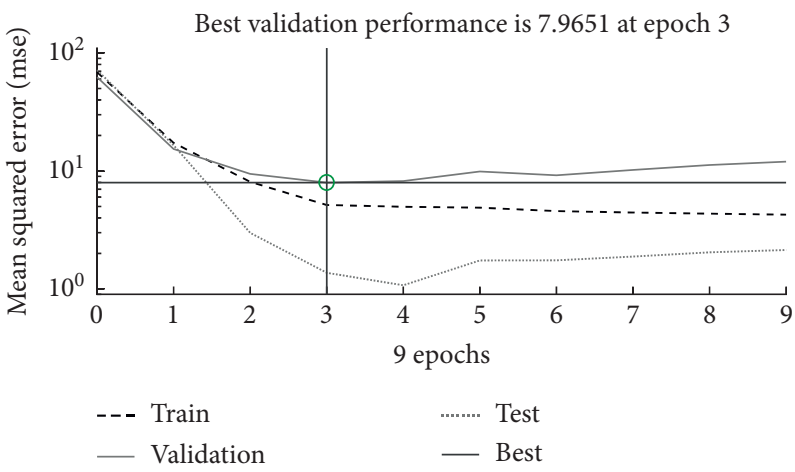

Figure 5: Neural network training iteration process.
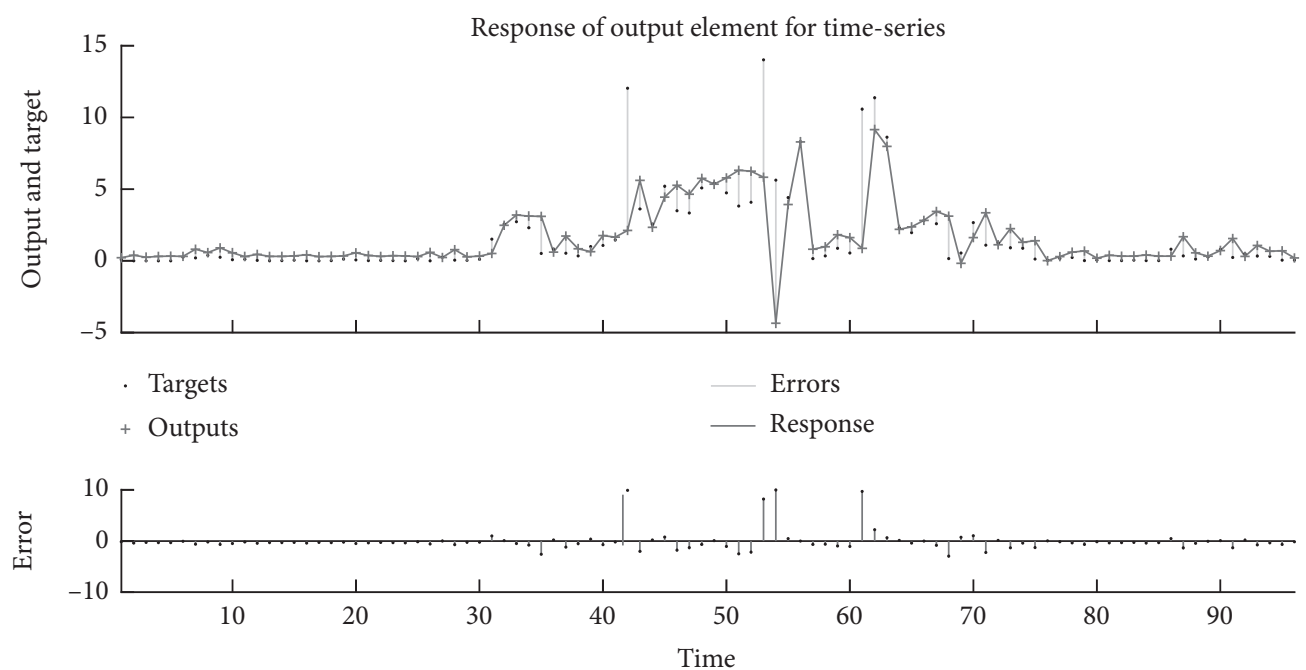

Targets - outputs

FIGURE 6: Diagram of neural network fitting results

TABLE 2: Regression debt leverage on enterprise investment efficiency model.

\begin{tabular}{lcccccccc}
\hline Variable & Debt & Debt $^{2}$ & Size & Cash & Grow & Constant & $R^{2}$ & Prob $>F$ \\
\hline \multirow{2}{*}{ Noinvest } & $1.446^{* *}$ & - & 0.104 & -1.657 & -0.073 & -2.611 & 0.0042 & 0.0053 \\
& $3.856^{* *}$ & $4.428^{*}$ & 0.281 & $-2.287^{* *}$ & -0.135 & -6.535 & 0.0063 & 0.0000 \\
\hline
\end{tabular}

supervision by creditors, leading to excessive corporate investment.

\section{Conclusion}

Through the above theoretical analysis and model verification of the relationship between state-owned enterprise debt leverage, diversified ownership reform, and investment efficiency, it is shown that, firstly, the diversified ownership reform can effectively improve the diversity of equity, the degree of equity integration, the degree of equity integration, and the degree of equity balance. It can also reduce the debt leverage of state-owned enterprises. Secondly, the debt leverage of state-owned enterprises and enterprise investment efficiency show a significant inverted U-shaped relationship. Furthermore, the diversified ownership reform can not only directly affect the investment efficiency of state-owned enterprises but also indirectly affect the investment efficiency of state-owned enterprises by acting on corporate debt leverage; at the same time, there is a time lag. Therefore, in the process of diversified reform of state-owned enterprises, we must pay attention to the proportion of equity to be introduced while actively introducing multiple ownership equity to make sure it can play a substantial role in the various production and operation decisions of the enterprise.

In this paper, the NARNET is used to evaluate the regression method of state-owned enterprise investment efficiency. Experiments show that the network model is more consistent with data simulation. We verified the relationship between diversified ownership reform, corporate debt leverage, and other factors and the investment efficiency of state-owned enterprises. The results verify that this method is effective and applicable. 
The investment efficiency evaluation of SOE is a complex problem. The shortcomings of this paper are mainly in the stage of data processing. We use the entropy method to weigh the data indicators. We do the above processing because we think that the impact of the above indicators on the investment efficiency is different. However, we did not test this hypothesis. In addition, this paper represents a regression analysis method, and we only use our method for comparison with the actual one. More experiments will be the next priority of this paper. In addition, we will consider more factors and technologies to be used to evaluate investment efficiency, such as investment strategy [24, 25], big data [26], and hybrid machine learning $[27,28]$ methods in the future.

\section{Data Availability}

All the data used in this study can be obtained upon request from the corresponding author.

\section{Conflicts of Interest}

The authors declare that they have no conflicts of interest.

\section{References}

[1] M. C. Jensen and W. H. Meckling, "Theory of the firm: managerial behavior, agency costs and ownership structure," Journal of Financial Economics, vol. 3, no. 4, pp. 305-360, 1976.

[2] S. T. C. Myers, "Determinants of corporate borrowing," The Journal of Finance, vol. 5, pp. 147-175, 1977.

[3] J. Tirole, The Theory of Corporate Finance, Princeton University Press, Princeton, NJ, USA, 2006.

[4] J. Sun, Y. Li, X. Zhao, and N. Zhang, "An evaluation on investment of research funds with a neural network algorithm in "double first-class" universities," Complexity, vol. 2020, Article ID 7496126, 8 pages, 2020.

[5] L. Qiang, J. Ji, and H. Ju, "Inefficient investment and debt structure: empirical evidence from China," Investment Research, vol. 3, pp. 66-79, 2014.

[6] L. Li, J. Wang, and X. Li, "Efficiency analysis of machine learning intelligent investment based on K-means algorithm," IEEE Access, vol. 8, pp. 147463-147470, 2020.

[7] Y. Li, L. Yang, B. Yang, N. Wang, and T. Wu, "Application of interpretable machine learning models for the intelligent decision," Neurocomputing, vol. 333, pp. 273-283, 2019.

[8] A. Bhagchandani and D. Trivedi, "A machine learning algorithm to predict financial investment," in Data Science and Intelligent Applications, pp. 261-266, Springer, Singapore, 2020.

[9] F.-M. Apipie and V. Georgescu, "Assessing and comparing by specific metrics the performance of 15 multiobjective optimization metaheuristics when solving the portfolio optimization problem," Economic Computation and Economic Cybernetics Studies and Research, vol. 53, no. 3/2019, pp. 39-58, 2019.

[10] S. Liu, "Auxiliary performance evaluation system based on text analysis," Dissertation, Harbin Institute of Technology, Harbin, China, 2015.

[11] Li Jiang, "Research on stock quantitative timing strategy based on support vector machine," Dissertation, Shenzhen University, Shenzhen, China, 2019.
[12] S. Wu, X. Yao, and G. Wu, "Environmental investment decision of green supply chain considering the green uncertainty," Complexity, vol. 2020, Article ID 8871901, 13 pages, 2020.

[13] Y. Lin, W. Liu, and Y. Wang, "An integrated approach using cross-efficiency and shapley value in performance evaluation," Economic Computation and Economic Cybernetics Studies and Research, vol. 53, no. 4, pp. 209-224, 2019.

[14] Y.-G. Song, Q.-L. Cao, and C. Zhang, "Towards a new approach to predict business performance using machine learning," Cognitive Systems Research, vol. 52, pp. 1004-1012, 2018.

[15] H. Ahmed, T. A. Jilani, W. Haider, M. A. Abbasi, S. Nand, and S. Kamran, "Establishing standard rules for choosing best KPIs for an e-commerce business based on google analytics and machine learning technique," International Journal of Advanced Computer Science and Applications, vol. 8, no. 5, pp. 12-24, 2017.

[16] S. Heilbrunn, N. Rabin, and S. Rozenes, "Detecting mutual configurations of applied planning strategies and performances in small and medium sized businesses with kernel based machine learning methods," Applied Soft Computing, vol. 61, pp. 1211-1225, 2017.

[17] H. Li, Q. Zhang, and Z. Zheng, "Research on enterprise radical innovation based on machine learning in big data background," The Journal of Supercomputing, vol. 76, no. 5, pp. 3283-3297, 2020.

[18] X. Wang, D. Zeng, H. Dai, and Y. Zhu, "Making the right business decision: forecasting the binary NPD strategy in Chinese automotive industry with machine learning methods," Technological Forecasting and Social Change, vol. 155, Article ID 120032, 2020.

[19] S. Richardson, "Over-investment of free cash flow," Review of Accounting Studies, vol. 11, pp. 159-189, 2006.

[20] H. Ma and Y. Wang, "Can deleveraging improve the investment efficiency of enterprises?-an empirical analysis based on the empirical data of Chinese listed companies," Securities Market Herald, vol. 5, pp. 13-20, 2017.

[21] H. Yang and L. Gong, "State-owned and private-owned diversified equity participation and company performance improvement," Economic Research, vol. 3, pp. 122-135, 2017.

[22] D. Cheng and Y. Dong, "Study on the productivity measurement and change trend of China's diversified ownership economy," Economics and Management Research, vol. 6, pp. 33-43, 2014.

[23] X. Du, Q. Zeng, and Y. Du, "Political connection, over-investment and corporate value: empirical evidence based on state-owned listed companies," Financial Research, vol. 8, pp. 93-110, 2011.

[24] T. K. Lee, J. H. Cho, D. S. Kwon, and S. Y. Sohn, "Global stock market investment strategies based on financial network indicators using machine learning techniques," Expert Systems with Applications, vol. 117, pp. 228-242, 2019.

[25] A. Wilinski and B. Kovalerchuk, "Visual knowledge discovery and machine learning for investment strategy," Cognitive Systems Research, vol. 44, pp. 100-114, 2017.

[26] T. A. Borges and R. F. Neves, "Ensemble of machine learning algorithms for cryptocurrency investment with different data resampling methods," Applied Soft Computing, vol. 90, Article ID 106187, 2020.

[27] K.-S. Moon and H. Kim, "Performance of deep learning in prediction of stock market volatility," Economic Computation and Economic Cybernetics Studies and Research, vol. 53, no. 2/ 2019, pp. 77-92, 2019.

[28] I. Stoica, "Solving system problems with machine learning," Studies in Informatics and Control, vol. 28, no. 2, pp. 119-132, 2019. 